\title{
Praxis for Accelerated Improvement in Research (PAIR)
}

\author{
Jovito C. Anito Jr. ${ }^{1}$, Auxencia A. Limjap ${ }^{1} \&$ Reynold C. Padagas ${ }^{2}$ \\ ${ }^{1}$ Research Office, José Rizal University, Mandaluyong City, Philippines \\ ${ }^{2}$ College of Nursing and Health Sciences, José Rizal University, Mandaluyong City, Philippines \\ Correspondence: Jovito C. Anito Jr., Research Office, José Rizal University, Mandaluyong City, Philippines
}

Received: January 14, 2020

Accepted: April 10, 2020

Online Published: April 18, 2020

doi:10.5430/ijhe.v9n3p248

URL: https://doi.org/10.5430/ijhe.v9n3p248

\begin{abstract}
This article introduces the Praxis for Accelerated Improvement in Research (PAIR) as a transformative research management paradigm drawn from the participatory action research program focused on research production and publication in a private higher education institution in Manila, Philippines. PAIR mentoring scheme upholds establishing a committed and caring relationship between the mentor and the mentee, thereby developing a shared vision towards research. PAIR mentoring further underscores the need to institute a university research infrastructure to support its research programs and initiatives. This participatory and transformative approach to research management tendered significant (and accelerated) improvement in the Scopus ${ }^{\circledR}$ metrics of the university. Reflecting from the researchers' and research participants' journey in implementing and embracing change and improvement in the university research programs, this article argues that researchers need to advance connectedness, conviviality, optimism, shared vision, and prudence in all aspects of research. This article thereby recommends learning and researching within the lens of participatory and transformative paradigm. The authors further recommend to higher education institutions establishment of a sustained mentoring program where mentors and mentees mutually agree and commit to advance the research vision of the university collectively. Finally, this article reasons in favor of an institutional research infrastructure that nurtures not just the knowledge and skills in research, but also the attitude and values of its research stakeholders towards research and the overall research program of the organization.
\end{abstract}

Keywords: research management, participatory action research, research mentoring, transformative paradigm

\section{Introduction}

Research is an integral component of higher education. The Philippine Commission on Higher Education (CHED) tags the universities as research and development laboratories in building the human capital for the global economy (CHED, 2009; Salazar-Clemeña, 2006). As research and development laboratories, Higher Education Institutions (HEIs) are enjoined to ensure that the research competencies of its faculty and students are nurtured. This entails the establishment of policies that could enhance the capacity of the higher education community to conduct discipline-based, policy-oriented, technology-directed, and innovative/creative researches that are locally responsive, and globally competitive (CHED, 2009).

To assist the Philippine HEIs in furthering research across all areas of higher education, several legal and administrative frameworks have been instituted. The Higher Education Act of 1994 (Republic Act [RA] 7722, 1994), for example, underscores the function of the State to ensure the advancement of learning and research, and mandates the institutions of higher learning to gear their programs to national, regional, or local development. This is embodied in the general principle that created the Commission on Higher Education. The CHED Memorandum Order (CMO) No. 46, s. 2012, on the other hand, provides focused support to research initiatives of HEIs towards technological innovation, economic growth, and global competitiveness. CMO No. 52, s. 2016 is another flagship initiative of CHED, aimed at addressing the pressing research challenges experienced by Philippine HEIs. Specifically, the memorandum assists HEIs in improving the research capabilities of its faculty and staff, and in upgrading its resources and research infrastructure. The memorandum further tenders support to HEIs in increasing its research productivity and raising its research quality and impact. The Philippines has likewise formulated its National Higher Education Research Agenda (CHED, 2009) and Harmonized National Research and Development Agenda (Decena \& Sobrevinas, 2017) as guidance documents for Philippine HEIs in identifying their research priorities and thrusts.

Despite the collective effort of the Philippine government and HEIs in advancing research, the Philippines consistently lags behind other countries in key research metrics. The 2018 Scimago Journal and Country ranking 
placed the Philippines at 67th among the 233 countries worldwide in terms of research document count (Scimago, 2018). This bibliometric analysis shows that Philippines trails even behind Bangladesh $\left(60^{\text {th }}\right)$ and some ASEAN neighbors Vietnam $\left(50^{\text {th }}\right)$, Thailand $\left(40^{\text {th }}\right)$, Singapore $\left(34^{\text {th }}\right)$, Indonesia $\left(24^{\text {th }}\right)$, and Malaysia $\left(23^{\text {rd }}\right)$. This suggests that while research is etched in government policies on higher education, Philippine HEIs need to introduce innovative research programs that could help accelerate the production and publication of research. This notion served as the foundation of this article, which primarily aimed to share the experience of Jose Rizal University in instituting a continuous quality improvement program for research.

\subsection{The Research Context}

José Rizal University (JRU) is a private higher education institution in the National Capital Region, Philippines. Like most Philippine HEIs, JRU struggles in the area of research, specifically in the publication of articles in reputable scientific platforms. As shown in Fig. 1, JRU registered only three Scopus® documents within a 10-year period (2008-2017). This suggests that while the university consciously endeavors to produce a number of researches, very few of these are actually published in reputable journals such as those that are indexed in Scopus $®$.

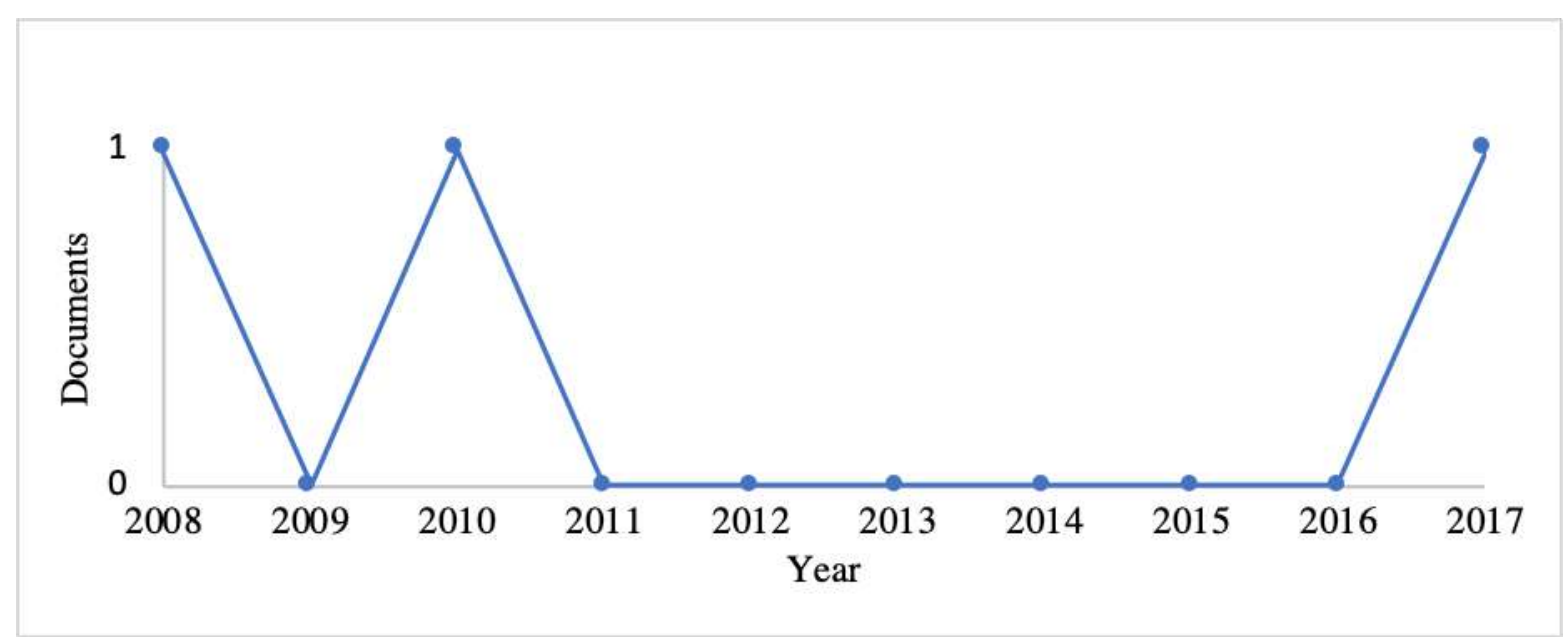

Figure 1. No. of JRU Scopus ${ }^{\circledR}$ documents between 2008 and 2017 (Source: www.scopus.com)

In 2012, the University Research Office (RO) introduced the Guided Research (GRes) Program. The program primarily aimed at building the research culture of the university. Specifically, the program started with the primary intention of developing essential research skills among JRU faculty and staff. The program involved a series of seminar-workshops about planning, designing, and undertaking small-scale research projects. The program also offered sessions on how to write research reports and design research posters. The topics were carefully timed, such that each topic was offered at the appropriate stage of the participants' research projects. The first six years of the program were a resounding success, as shown in the number of researches completed by the program participants (Fig. 2).

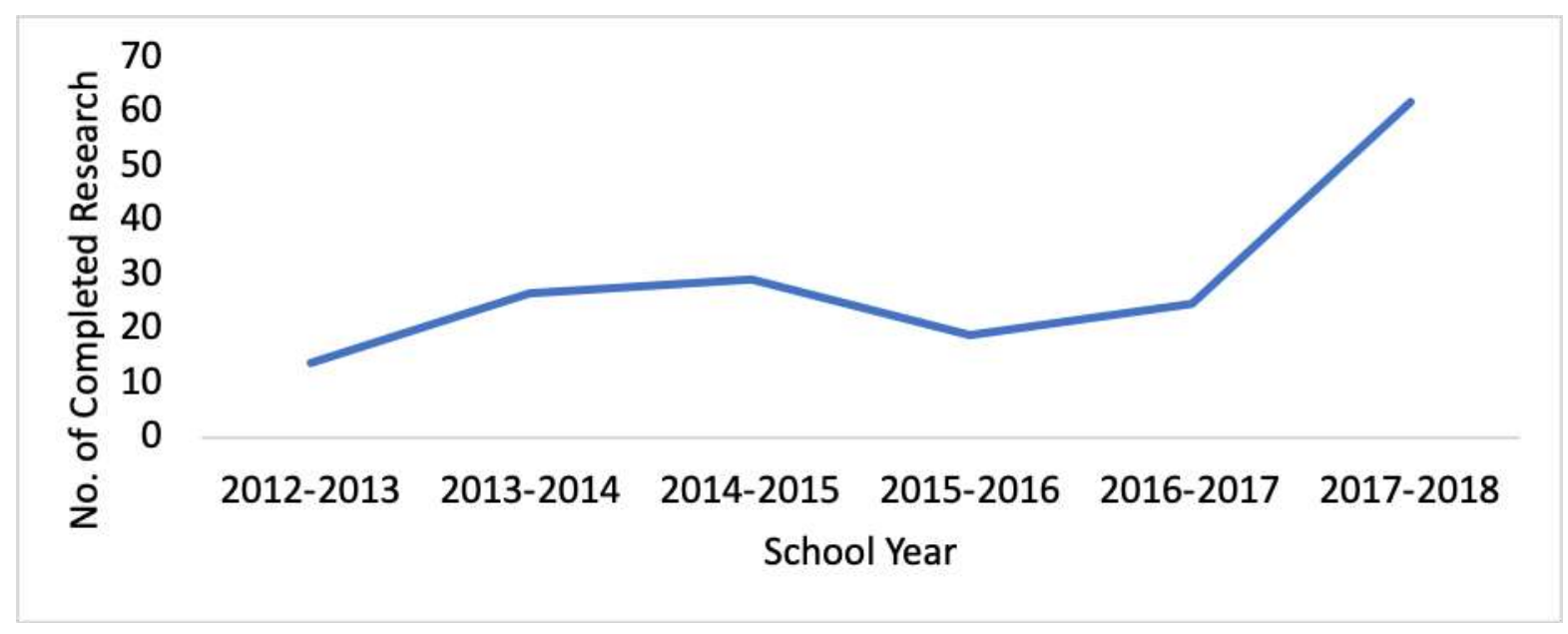

Figure 2. No. of completed research projects during the first six years of the GRes program 
The 176 research outputs during the first six years of GRes (Fig. 2) clearly demonstrates the research capability of JRU faculty and staff, a realization of the GRes program's primary objective. Cognizant of the advanced needs of some faculty and staff, especially those who have already completed GRes in the past, the university introduced three GRes groups in SY 2018-2019. The basic group was intended for participants who have not completed any of the previous GRes programs. The intermediate group was for those who have already completed a previous GRes program and those who teach research courses. The advanced group was for participants who have already completed a previous GRes program and have already published their research output in any research dissemination platform. Aside from the three GRes groups, the university also introduced the Community Outreach Research and Evaluation (CORE) group composed of those who were doing research on the university's community outreach programs. The university also funded institutional and collaborative research projects. These initiatives have significantly improved the quality of research at JRU. As can be seen in Fig. 3, the university registered an additional five Scopus ${ }^{\circledR}$ documents in 2018, a significant increase from the previous 10-year data (Fig. 1).

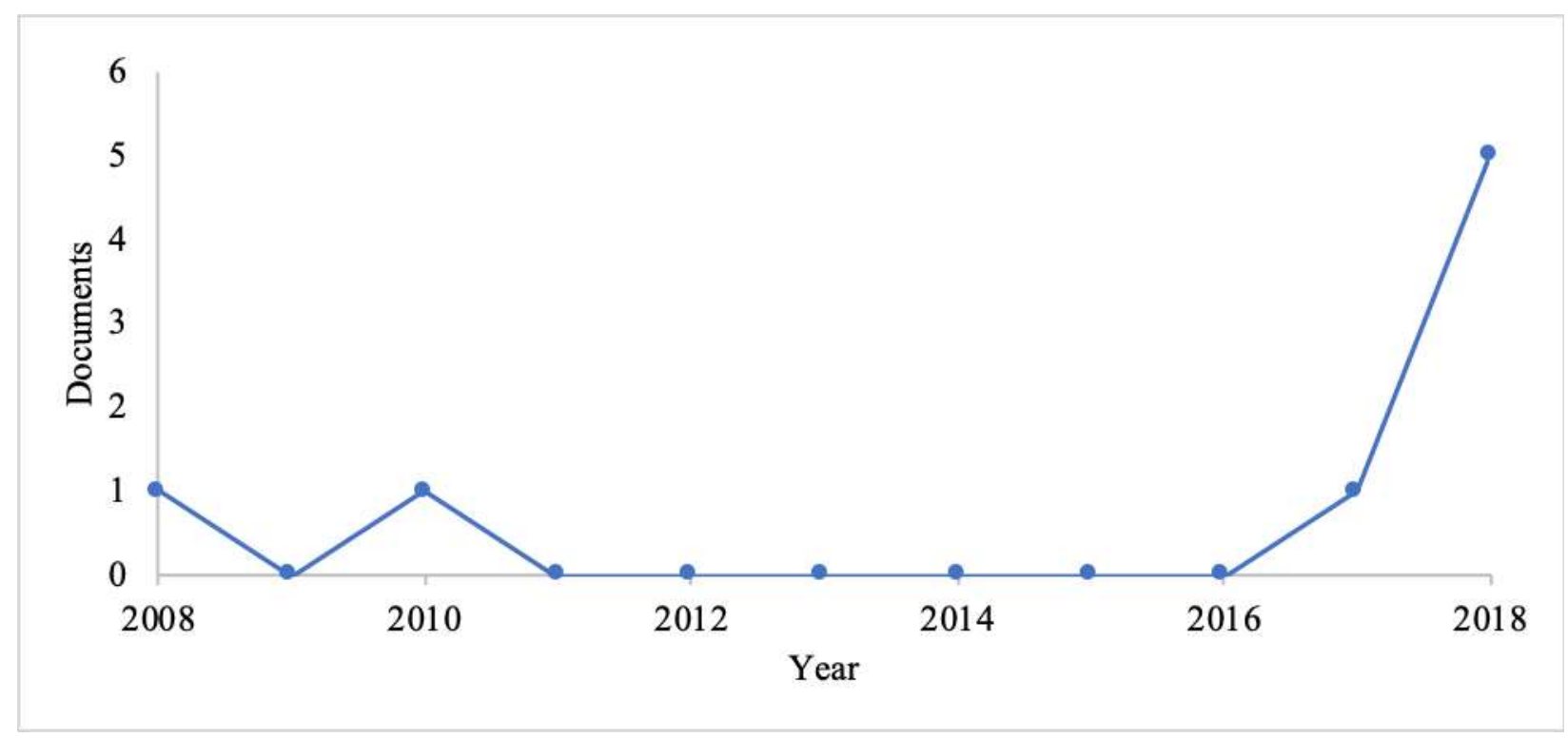

Figure 3. No. of JRU Scopus ${ }^{\circledR}$ documents from 2008 and 2018 (Source: www.scopus.com)

While the increase in Scopus ${ }^{\circledR}$ documents indicates a significant improvement in the quality of research at JRU, it likewise bears the university's meager metrics of quality research outputs. This suggests that the university needs to take more aggressive steps towards accelerating the publication of quality researches. This is the core of this article. Specifically, this article will showcase how JRU managed to fast-track the improvement of its research metrics. This article will likewise describe the support mechanism that was instituted to sustain the said improvement.

\subsection{Reflexivity, Positionality, and the Researchers}

This article will advance from the lens of the qualitative research paradigm, specifically within the Participatory Action Research (PAR) tradition. In order to accentuate the active engagement of the researchers within the studied context, the first-person perspective will be observed throughout this article. That is, the first-person pronouns will be used to refer to the researchers in the succeeding sections of this article, unless in parts where the use of such may cause ambiguity or inaccurate reference to a specific person or group.

Reflexivity is an important element of a qualitative inquiry (Naples \& Sachs, 2000), most especially in PAR, because of the need to address the insider-outsider duality in the research process (Finefter-Rosenbluh, 2017). Reflexivity is a process that researchers undertake to critically examine their assumptions and thinking relative to those of others in a studied context (Anito, Morales, Torres, Gonzales, \& Ganeb, 2019). Reflexivity entails looking inwards and outward concerning the position of the researcher in the research process (Shaw \& Gould, 2001), specifically how their experiences, knowledge, and social positions might impact the research process (Pillow, 2003). Because the "self" and "others" are integral to self-understanding (Stronach, Garratt, Pearce, \& Piper, 2007), reflexivity is best demonstrated as an interaction of the self and others (Anito, Morales, Torres, Gonzales, \& Ganeb, 2019). In this article, this entails articulating our reflexive mechanism across all stages of the research method, where paradigmatic 
positions intersect. The succeeding paragraphs are dedicated to describing our insider-outsider perspectives of the studied context. Specifically, we introduce ourselves in the light of the positions that we take as researchers and at the same time as participants of the research.

Author 1 - I am currently the research associate of the JRU research office. I assist the research director in planning and implementing the university's research programs. JRU was an unfamiliar environment for me when I joined the university last October 2018. This was particularly helpful to me because I had an outsider perspective on the research landscape of the university. As a researcher however, i have positioned myself in the lens of the research director and the faculty and staff engaged in research. This insider perspective facilitated the critical assessment of the ongoing research initiatives of the university towards identifying the areas for improvement.

Author 2 - I am the research director of the JRU research office. My insiderness of the studied context is two-fold as a researcher and as a research mentor. Prior to my appointment as a research director, I had been engaged with the JRU research as one of the mentors of the Guided Research (GRes) program of the university. As a mentor, my task was to deliver lecture-workshops on pre-assigned topics. I was also assigned as a mentor to some researchers and research groups across all stages of the research process. As an outsider of the system, I maintained my non-JRU perspective on research conduct in all my GRes engagements with JRU. By non-JRU, I refer to the research culture of the university where I spent most of my time, as faculty, as an administrator, and a researcher.

Author 3 - I have been a college faculty of Jose Rizal University for almost 14 years now and have been active in research. I started as a participant then eventually became a mentor in G-Res. I have witnessed how research initiatives were done in JRU because of the compelling needs for research production and quality research publication. As a participant in G-Res, I noticed that each faculty was driven by certain drivers to be able to conduct research. Admittedly, most of us were not too focused on quality publication. A few of us were focused on incentives, while others were just truly motivated to hone their research competencies. Some were just diligent of their bosses that they committed themselves to G-Res. As a mentor, I have seen the need to publish in reputable journals such as those that are ISI or Scopus-indexed, not just to produce and present a paper. I also discovered that collaboration works very well despite team diversity. My goal was to help others hone their research competencies as I also intensify mine - mentoring is twice learning, as I put it. We get to maximize each member's capacity to enable completion of our research outputs for publication. As a mentor, I have identified several needs affecting the HEIs and the whole of research and development across disciplines where research is deemed imperative as a problem-solving mechanism - practical, human-centered, and iterative.

\section{Review of Related Literature}

\subsection{Research in Philippine Higher Education}

The advancement of research in higher education is a legal stipulation emphasizing the State policy to foster continuing intellectual growth and advance learning and research (Republic Act [RA] 7722, 1994). With assistance from the Commission of Higher Education (CHED), higher education institutions must advance research and development in higher learning, alongside with instruction and community extension. As the overseer of higher learning, CHED sets the research direction of all higher learning institutions, establishing administrative frameworks, and appropriating funds for research and development programs. The CHED Memorandum Order No. 52, s. 2016, for example, articulates the strategic thrusts and pathways for research and innovation in higher education. The CMO primarily aimed to actualize the potential of higher education institutions as platforms for knowledge production and advancement, engines of development through responsive and relevant research programs, and producers of multi-specialists, creators, problem-solvers, collaborators, inventors, thinkers and innovators who can examine phenomena and explore new frontiers. The CMO postulated the three interrelated pathways which specify the key principles, programs, and mechanisms for the research ecosystem in Philippine higher education. Pathways to Equity affirms the principle of inclusiveness in research and the maximum participation of bona fide researchers along the career span, working in research groups or consortia. Pathways to Relevance ensures that HEIs should engage in research that could deepen our understanding of ourselves as a nation, and discover practical, evidence- and science-based answers to real-world, social, economic, and environmental challenges of the society. Pathways to Advancement initiates a mechanism to motivate, reward, and recognize the work of Philippine HEI researchers. The higher education research is also guided by the National Higher Education Research Agenda (CHED, 2009) and the Harmonized National Research and Development Agenda (Decena \& Sobrevinas, 2017). 


\subsection{Participatory Action Research for Teacher Professional Development}

Participatory Action Research (PAR) is an umbrella term comprised of reflective and participatory approaches to action-oriented and improvement research. PAR approaches and methods have seen an explosion of recent interest in the social sciences, involving collaborative research and education and action, which are oriented towards social change (Kindon, Pain, \& Kesby, 2007; Mills, 2011) and improvement of practice (Mertler, 2017). In an educational setting, PAR involves researchers and participants working together to examine specific aspects of educational practices in order to introduce improvement. Within the Action Research family, PAR is seen in many pieces of research to benefit the education field by fostering collaborative perspective characteristics of Action Research (Morales et al., 2019). It seeks to bring together action and reflection, theory and practice, in participation with others, in pursuit of practical solutions to issues of pressing concern to people, and more generally, the flourishing of the individual and their communities (Reason \& Bradbury, 2008).

Participatory Action Research advances the teacher continuing professional development. McNiff and Whitehead (2002) argued that PAR was developed mainly by academics in higher education who saw it as a useful way of working in professional development. In fact, action research is used in many professional learning contexts, both formally and informally (McNiff \& Whitehead, 2002). As a form of professional development, action inquiries revolve around the question, "What can I/we do differently to get better performance or results?". For McNiff and Whitehead (2002), this question has a social implication emphasizing the intention to improve one's professional practice to benefit himself and others.

The transformative element of Participatory Action Research can be traced back to the emancipatory educator Paulo Freire who developed a community-based research process to support people's participation in knowledge production and social transformation (Kindon, Pain, \& Kesby, 2007). In higher education, PAR is a potential framework for transformative social learning with a change agenda. Mertler (2017) argued that action research, when taken as a participatory and collaborative venture, promotes more systemic types of improvement. This is because sharing of responsibilities in a collaborative process brings together different perspectives, ideas, experiences, and resources (Mertler, 2017).

Applying PAR, the stakeholders of higher learning engage in cycles of inquiry and practice within the system, primarily to satisfy the continuous need for development or change (Bradbury, Lewis, \& Embury, 2019). PAR in higher education is basically engaging educators and education professionals in reflective and critical evaluation of their respective practices. This entails collecting information about current practices and performances and utilizing the said information in developing plans for improved professional practice. McNiff and Whitehead (2002) simplified this process as identifying a problematic issue, imagining a possible solution, trying it out, evaluating it, and changing the practice in the light of the evaluation. Other models of action research range from simple to complex (Mertler, 2017) cycles. Stringer (2007) presented a simple interacting spiral of Look, Think, Act routine, while Riel (2008) proposed a progressive problem-solving model of planning, taking action, collecting evidence, and reflecting.

Self-reflective practice is a vital element of action research. By self, we mean either our professional practice or that of the system where we play a crucial role. As a reflective practice, PAR also underscores the researchers' and participants' paradigmatic shift brought about by the process of change. A paradigm shift within the higher learning ecosystem is crucial in order to sustain and accelerate improvement. The paradigm shift is specifically characterized by empowerment, intellectual engagement, and professional growth. Mertler (2017) argued that when educators collect their data in order to assist in making decisions about their practices, they become empowered and intellectually engaged. Parsons and Brown (2002) also argued that educators must engage in action research to improve their problem-solving skills and their attitude towards professional development and consequently increase their confidence and professional self-esteem (Parsons \& Brown, 2002).

\subsection{Transformative Learning}

The theory that best describes how meaningful adult learning takes place is Jack Mezirow's Transformative Learning. He describes it as the process by which we change our frames of mind, meaning perspectives, and habits of mind. By gaining control of our beliefs, values, and mindsets, we can make objective and responsible decisions.

The four main components of transformative learning are experience, critical reflection, reflective discourse, and action. The environment has to provide the experience which will encourage the learner to engage in critical reflection. This is the stage where the learners start to doubt their deeply held beliefs about the experience. They undergo what is referred to as a disorienting dilemma. If there is conflict in the experience of acquiring the new 
knowledge and what they know all along, the learner engages in content reflection. Limjap, Miciano, and Mojica (2016) asserts that this process of realization and self-rectification lead learners to a transformation of their conceptions and alteration of their prior knowledge. When the learners look for processes or problem-solving strategies to find solutions to conflicts they encounter, process reflection takes place. When they examine their assumptions, long-held values, and beliefs, they undergo premise reflection. It takes maturity to be able to engage in critical reflection. Nevertheless, this component of transformative learning leads the learners to the next component, which is reflective discourse. This takes the form of higher-order thinking skills of synthesis and analysis. Learners decide to articulate the disorienting dilemma, the decision to make a change, and the process they took to achieve the change. At this point, the learners have to make sense of their new roles and current meaning scheme by taking immediate action. It can be in the form of a paradigm shift, change in world view, trying different models or a new perspective, or navigating new challenges.

Transformative learning empowers learners to become dynamic and proactive. This is made possible by the following 10 phases of Transformative Learning. According to Mezirow and Taylor (2009), these need not come in the given order. The first phase is when earners come across situations that challenge their existing interpretation or prior knowledge. They are confused and disoriented, and they start to doubt themselves. The second phase happens when learners realize the need to examine their understanding of concepts and processes upon which the new knowledge is anchored. In the third phase, learners critically assess the source of their interpretations of concepts and processes. They compare interpretations with peers or teachers and try to negotiate and reconcile their differences. Learners in the fourth phase recognize the need for a change of their interpretation to a more intelligible explanation or interpretation of the concepts. This is the start of a transformation of mindset, perspective, and understanding of concepts and processes. Phase 5 happens when learners assume new roles, relationships, and actions on newly acquired knowledge, skills, and understanding. As they explore their new options, they discover new ways of applying their ideas to different situations. Phase 6 is when learners are empowered to plan a course of action for any problem-solving situation. They learn to inquire and take action to find answers to the questions that they raise. In phase 7, learners are able to implement their plan of action and focus on the product of their inquiry as well as the concepts and processes involved. Learners in phase 8 try new roles in many different but relevant contexts, where they can apply their newly acquired skills and understanding. In phase 9, learners build their competence and self-confidence in the newly acquired roles and understanding in different situations. Phase 10 extends phases 8 and 9 to many real-life situations that are relevant to the newly acquired skills and understanding. Learners not only integrate new knowledge in other fields but reintegrate the new mindset, frames of mind, and meaning perspectives in their lives.

\subsection{Expansive Learning}

A close relative to transformative learning is learning by expanding. Expansive learning is a transformative paradigm of the system, and organizational management focused on constructing and implementing a qualitatively new way of function for itself by dealing with its internal contradictions (Engeström, 2016; Engeström, 2001; Engeström, 1987) characterized by three central features (Engeström, 2007; Engeström, 2004). First, expansive learning is transformative learning where improvement of activity is brought about by the novel tools, models, and concepts. Second, expansive learning is horizontal and dialogic learning that creates knowledge and transforms an activity through actions of bridging, boundary-crossing and negotiating. Third, expansive learning is identified as subterranean learning that blazes cognitive and trails that are embodied and lived but unnoticed. For Engeström (2007), these trails serve as anchors and stabilizing networks that secure the viability and sustainability of the new concepts, models, and tools, thus making the multiactivity terrains knowable and livable.

Expansive learning underscores "instability" and "contradictions" of knowledge and processes within activities, groups, and organizations. For Engeström (2001), this is because people and organizations are all the time learning something that is not stable, not even defined or understood ahead of time. It is, therefore, essential to learning new models and processes that are not yet known, and learning while the models and processes are created. Engeström (2001) proposed a model of expansive learning composed of seven stages. The first stage is questioning the current activities and evaluating the current models and processes. The second stage comprises a historical analysis and actual empirical analysis of the current models and activities and the performance indicators of the system or organization due to the current models and activities. The third stage is on modeling new solutions followed by formulating the new model in the fourth stage and implementing such a new model in the fifth stage. The sixth stage is the reflective analysis of the implementation of the new model, and the final stage is the formulation of the new practice. As a transformative learning paradigm, the seven stages of expansive learning resonate much with the improvement and change agenda of participatory action research. Hence, along with action research, PAR, and 
transformative learning, expansive learning informed much of the research management activities described in this article.

\section{Conceptual Framework}

This study advances a research management framework informed primarily by the professional development and change agenda of Participatory Action Research (Bradbury, Lewis, \& Embury, 2019; Kindon, Pain, \& Kesby, 2007; McNiff and Whitehead, 2002; Mertler, 2017, Mills, 2011; Morales et al., 2019, Reason \& Bradbury, 2008), the iterative inquiry of Action Research (Riel, 2008; Stringer, 2007), the paradigm shift of transformative learning (Limjap, Miciano, \& Mojica, 2016; Mezirow \& Taylor, 2009), and the uncovering of new models of Expansive Learning (Engeström, 2016; Engeström, 2007; Engeström, 2001; Engeström, 1987). In order to simplify the process, the research management initiatives described in this article builds on the work of Stringer (2007) accentuating organizational change and improvement through a simple spiral of Look, Think, and Act routine. The participatory and transformative learning traditions of Mezirow and Taylor (2009) and Engeström (2001) were likewise adapted to enhance the success of the improvement program. Table 1 illustrates the convergence of participatory action research, transformative learning, and expansive learning, as used as the framework of the research management program introduced in this article.

Table 1. Convergence of Action Research, Transformative Learning, and Expansive Learning as Transformative Paradigm in Research Management

\begin{tabular}{|c|c|c|}
\hline $\begin{array}{l}\text { Action Research } \\
\text { (Stringer, 2007) }\end{array}$ & $\begin{array}{l}\text { Transformative Learning } \\
\text { (Mezirow \& Taylor, 2009) }\end{array}$ & $\begin{array}{l}\text { Expansive Learning } \\
\text { (Engeström, 2001) }\end{array}$ \\
\hline Look & $\begin{array}{l}\text { Challenging prior knowledge and existing interpretation; } \\
\text { Examining personal understanding of concepts and processes }\end{array}$ & $\begin{array}{l}\text { Questioning; Historical } \\
\text { Analysis } \\
\text { Actual Empirical } \\
\text { Analysis }\end{array}$ \\
\hline Think & $\begin{array}{l}\text { Critical analysis of the sources of interpretations of current } \\
\text { processes; Recognizing the need to change interpretations of } \\
\text { concepts and processes; Planning a course of action }\end{array}$ & $\begin{array}{l}\text { Modeling New } \\
\text { Solutions; Formulating } \\
\text { New Model }\end{array}$ \\
\hline Act & $\begin{array}{l}\text { Assuming new roles, relationships and actions } \\
\text { Implementing the plan of action; Trying out the new roles in } \\
\text { different but relevant contexts; Building confidence with the } \\
\text { new roles; Integrating new knowledge in other fields }\end{array}$ & $\begin{array}{c}\text { Implementing New } \\
\text { Model } \\
\text { Reflecting on the New } \\
\text { Model } \\
\text { Consolidating the New } \\
\text { Practice }\end{array}$ \\
\hline
\end{tabular}

\section{Method}

The change and improvement requirements in the research were articulated to us by the university's vice president for administration during our orientation meeting at the commencement of our engagement with JRU - AAL as research director and JCA as a research associate. The meeting stressed the usual recommendations of accreditation and evaluation bodies as regards the quality of research in the university. As indicated in the context section of this article, the university has produced a relatively good number of research outputs but skimpy in terms of publications in reputable journals. The need to accelerate research production and improve publication metrics, specifically in Scopus, was clearly articulated in that meeting. The succeeding sections describe our response to the said research requirements of the university.

\subsection{Look}

We began our journey in employing the transformative paradigm in research management challenged by the well-articulated university requirements in research metrics. Our first step was to examine the research system and reflect on its current models, understandings, processes, and interpretations. Specifically, we built on the existing Guided Research (GRes) program of the university. One of the key features of GRes is to offer a series of lecture-workshops to its participants throughout the whole school year. Topics have been identified and calendared at the start of the school year, and resource speakers have been identified. Some of these resource speakers were 
outsourced from outside JRU. AAL, for example, used to be a resource speaker and mentor of GRes before she was appointed as research director of the university. The formal structure and clear guidelines and mechanics of GRes significantly facilitated our initial change efforts.

In order to explore the GRes participants' current knowledge, interpretations, and processes as regards research, we identified ways to have more extended engagement with them. With the help of RCP, one of the university researchers, we introduced more topics to the GRes program and assumed delivery of the remaining sessions of GRes. Besides the usual research capacity-building objectives, we aimed to better understand the university's research culture through active interaction, exchange of ideas, and demonstration of current skills and knowledge of research, for us to formulate improvement actions consequently. We also examined the existing research documents of the research office, such as the research policies and guidelines, research plans, annual reports, among others. In select meetings of the research office, we also invited the previous research director to help us understand the context better. Meetings and correspondence of AAL with the academic council, the vice president for academics, and other officers and unit heads of the university further helped us build a holistic picture of the system. Our prolonged engagement with GRes participants and review of research files and coordination with the previous research director and other officers led us to identify the significant needs of the university's stakeholders of research. Table 2 illustrates these needs. Table 2 also exemplifies the participatory nature of the change agenda that we initiated. By involving all stakeholders of the system being examined, we were able to formulate specific action plans to accelerate the improvement of the university's research metrics.

Table 2. Needs and requirements of JRU research stakeholders

\begin{tabular}{|c|c|}
\hline $\begin{array}{c}\text { Research } \\
\text { Stakeholders }\end{array}$ & Needs and Requirements \\
\hline \multirow{3}{*}{$\begin{array}{l}\text { Guided Research } \\
\quad \text { (GRes) }\end{array}$} & Continuous mentoring and monitoring mechanism (including assignment of committed \\
\hline & mentor who can offer guidance until the publication stage) \\
\hline & Capacity-building activities on research publication standards \\
\hline Participants & $\begin{array}{c}\text { Enhanced incentive package for publications in Scopus and other reputable journals (as a } \\
\text { form of motivation) }\end{array}$ \\
\hline \multirow{3}{*}{$\begin{array}{l}\text { Other faculty and } \\
\text { staff }\end{array}$} & Guidance in literature synthesis and identification of research gaps \\
\hline & Guidance in preparation of research proposals for university funding \\
\hline & Committed mentors \\
\hline \multirow[t]{3}{*}{ Research Office } & $\begin{array}{l}\text { Faculty and staff who have the inner drive to engage in research (who can establish and } \\
\text { sustain committed engagement in research) }\end{array}$ \\
\hline & University support to the programs and initiatives of the research office \\
\hline & $\begin{array}{l}\text { Increased number of publications in Scopus and other reputable journals as indicator of } \\
\text { quality research production }\end{array}$ \\
\hline \multirow{3}{*}{ University } & Satisfaction of accreditation requirements on research \\
\hline & Reputability of research in the university \\
\hline & $\begin{array}{l}\text { Accredited Research Ethics Committee to ensure ethical conduct of research especially on } \\
\text { human samples and human end users }\end{array}$ \\
\hline \multirow{2}{*}{$\begin{array}{l}\text { Colleges and } \\
\text { other academic } \\
\text { units }\end{array}$} & $\begin{array}{l}\text { Guidelines on research processes (application for support to presentation in international } \\
\text { conferences, application for publication incentive, etc...) }\end{array}$ \\
\hline & University research agenda and other frameworks for appropriate conduct of research \\
\hline
\end{tabular}

\subsection{Think}

From Table 2, the emphasis on the need for committed mentors and continuous mentoring and monitoring mechanism was drawn from the participants' reflection on the existing GRes processes. The participants specifically admitted that the availability of their respective mentors and scheduling of meetings and consultations were among their primary concerns. Cognizant of the rigorous and time-consuming nature of research, the participants further expressed their desire to increase the incentives for publication. The participants were also asked to reflect on their experience since they began their journey in GRes. Specifically, they were asked to reflect on their motivation why 
they joined the program as well as the challenges they encountered. These reflections helped us identify the needs of those who have no GRes experience. Their reflections informed us of the need to dedicate lectures and workshops on literature synthesis so beginning researchers can identify research gaps, formulate their conceptual frameworks, and articulate their research objectives. Beginning researchers also need guidance in the preparation of proposals that merit university financial support. The university, on the other hand, reiterated the need to establish reputability in our research metrics which translates to satisfying the accreditation requirements on research and achievement of other global research reputability indicators.

The identified needs and requirements of research stakeholders can be resolved into two themes - sustained mentoring and research infrastructure. Sustained mentoring entails the constant engagement of faculty and staff researchers with their mentors on a mutually agreed mechanism. Research infrastructure refers to university research policies and guidelines that nurture research talents among its faculty and staff. The next section, "Act", will elaborate on these research management groundings through specific research programs.

\subsection{Act}

Sustained mentoring was deemed a crucial element of our change agenda for JRU research. This was brought about by the participants' recognition of the effect of fragmented mentoring sessions with their respective mentors. Responding to this, the JRU research office introduced the Praxis for Accelerated Improvement in Research (PAIR) in our GRes program. PAIR is a research mentoring strategy anchored on a transformative research management paradigm. There are two significant features of PAIR mentoring. First, it offers a "buddy" system in the conduct of research. Researchers under the GRes program always come in pair. Pair also means the number of mentees under one mentor per year. Pair also means that each mentee of the current year shall become a mentor in the following year and the years after that. Fig. 4 illustrates this mentoring scheme further.

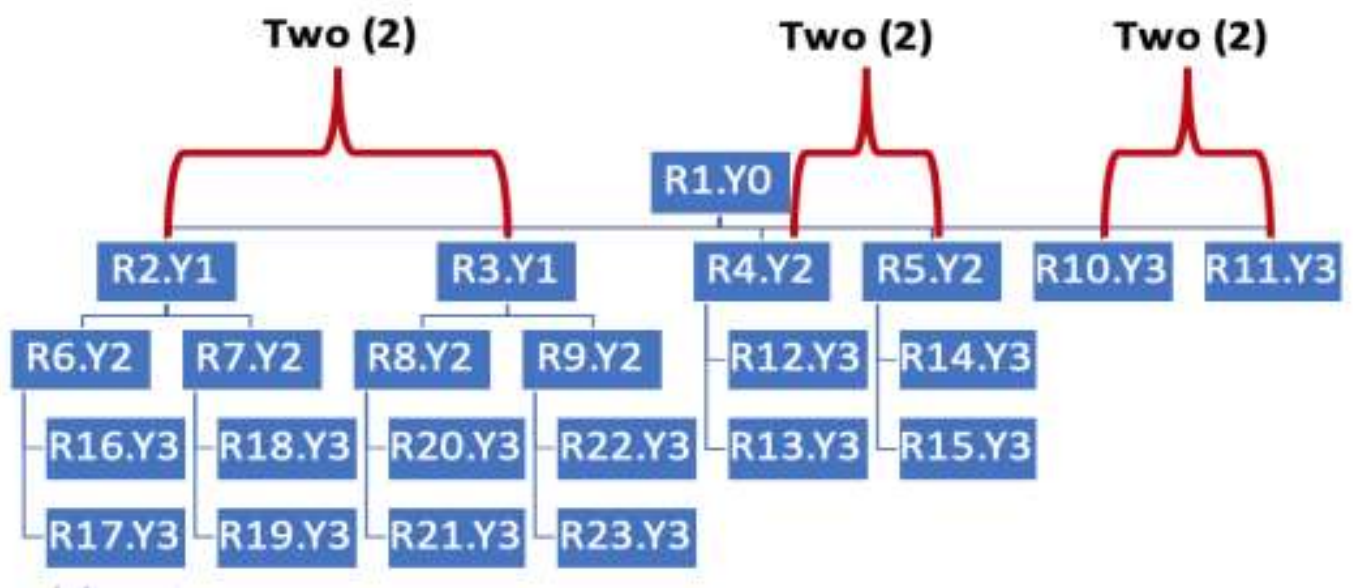

Figure 4. The PAIR Mentoring Scheme

The pair mentoring scheme (Fig. 4) suggests that each researcher who published in year 0 (SY 2018-2019) will mentor at least two researchers every year for the next three years. Each mentee who published in year 1 (Y1) will mentor at least two researchers every year for the next two years, and each mentee who published in year 2 (Y2) will mentor at least two researchers on year 3 (Y3). Following this scheme, with us (JCA, AAL, RCP) as committed mentors for year 0 (Y0), JRU will produce at least 69 publications in Scopus at the end of SY 2022-23 (Y3).

Accompanying the PAIR mentoring scheme is the mentoring and monitoring form (Fig. 5). The form primarily aims to document the mentoring sessions of the mentor and the mentee. The mentoring and monitoring form resembles the prescription receipt given by medical doctors to their patients right after the consultation. The GRes mentoring form asks the mentee every consultation the general nature of the concern ranging from literature synthesis to ethics and quality of research. The form also asks the mentee to provide the details of the concern. In a dedicated column, the mentor will provide specific instructions and suggestions relative to the specific concerns of the mentee and his overall impression of the submitted output. 

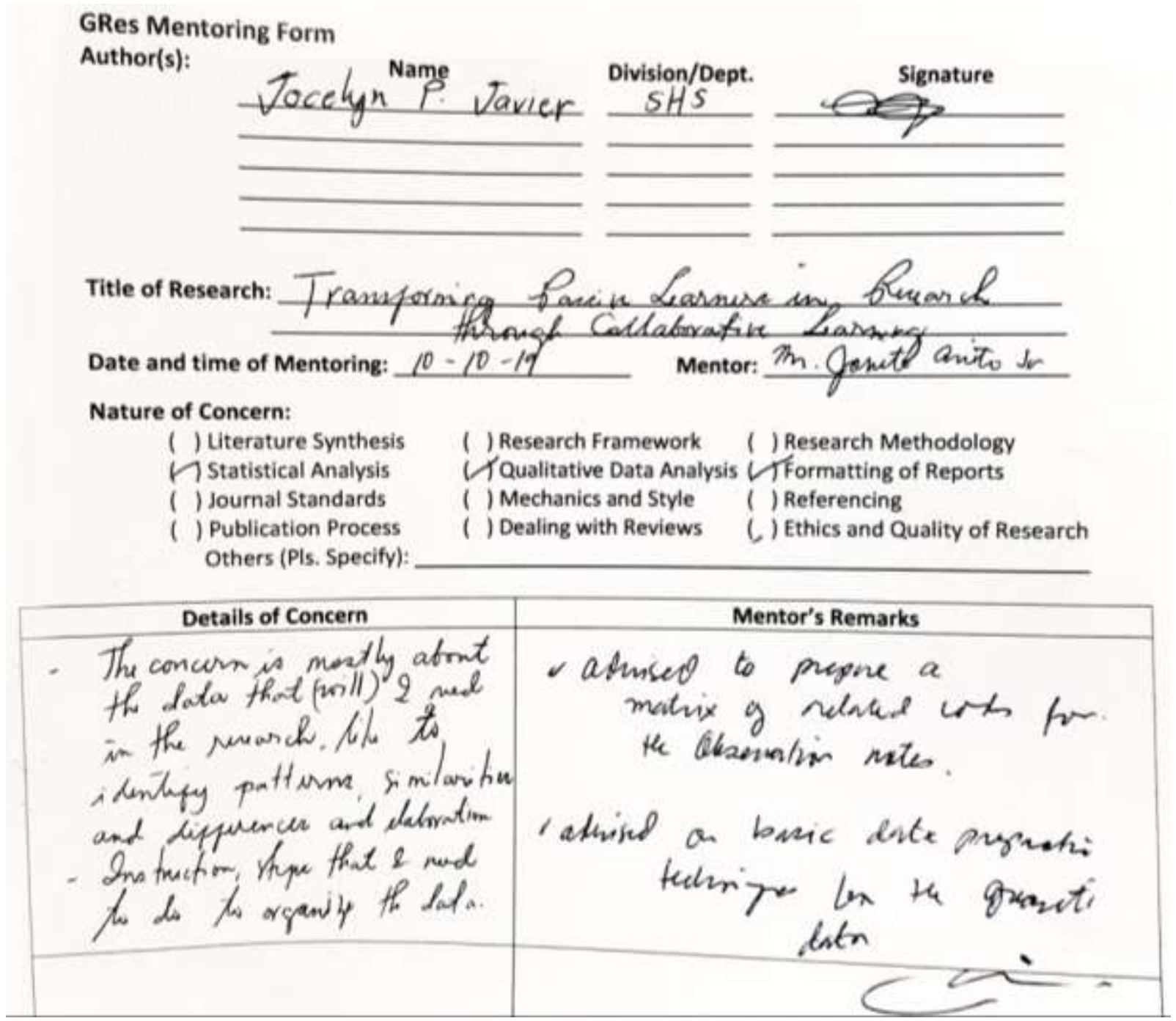

Figure 5. Sample of a Completed GRes Mentoring Form

Fig. 5 is an example of a completed GRes mentoring form. In this session, the mentee came to see the mentor to request assistance in analyzing the collected data. The mentor walked the mentee through some coding techniques for qualitative data and some guidelines in presentation statistical reports. It is also noteworthy to mention that consultation time is arranged by the mentee with the mentor, and the schedule of consultation is mutually agreed upon by the two.

The JRU research infrastructure was likewise improved in terms of the support mechanism for research presentations at national and international conferences. The international conference, for example, has increased its support coverage to include even airport transfer and visa processing expenses. The per diem allowance was also increased to about $43 \%$. This increased support coverage further comes with tightening measures in terms of the type of conferences the university will support. The revised guidelines on Research Presentation Incentives (RPI) require conferences whose previous conference proceedings have been indexed in Scopus or whose current conference will be indexed in Scopus. RPI also supports conferences that are affiliated with Scopus-indexed journals.

Another significant milestone in JRU research infrastructure is the revised Journal Publication Incentives (JPI). The revised JPI offers incentives to research published in scientific platforms under five categories or tiers. Table 3 presents the different classification of incentives under the revised JPI of the university. 
Table 3. The Publication Incentive Categories of the Revised Journal Publication Incentives of JRU

\begin{tabular}{|c|c|}
\hline $\begin{array}{l}\text { Incentive } \\
\text { Category }\end{array}$ & Description \\
\hline Tier 5 & Scopus-Indexed Journals in the $75^{\text {th }}$ percentile or higher based on Citescore Rank \\
\hline & Scopus-Indexed Journals within $50^{\text {th }}$ and $74^{\text {th }}$ percentiles based on Citescore Rank \\
\hline Tier 4 & $\begin{array}{c}\text { Journals indexed in WoS (ISI) limited to Science Citation Index (SCI), Social Science Citation Index } \\
\text { (SSCI), Arts and Humanities Citation Index (AHCI), Emerging Sources Citation Index (ESCI) and } \\
\text { listed in Q1 and Q2 of Scimago. }\end{array}$ \\
\hline & Scopus-Indexed Journals below the $50^{\text {th }}$ percentile based on Citescore Rank \\
\hline Tier 3 & $\begin{array}{l}\text { Journals indexed in WoS (ISI) to be limited to SCI, SSCI, AHCI, ESCI citation indices and those } \\
\text { listed in Q3 and Q4 of Scimago. }\end{array}$ \\
\hline Tier 2 & Scopus-Indexed Conference Proceedings \\
\hline Tier 1 & Refereed Journals indexed in databases other than those in higher tiers \\
\hline \multicolumn{2}{|c|}{$\begin{array}{l}\text { Tier } 1 \text { incentives, representing the lowest tier, may be availed for articles published in peer-reviewed journals. Tier } 2 \\
\text { is for full research papers published in conference proceedings indexed in Scopus or Web of Science (WoS). Tier } 3 \\
\text { covers articles published in percentile } 50 \text { (P50) and below for Scopus-indexed journals and Quartiles } 3 \text { and } 4 \text { (Q3 } 3 \\
\text { and Q4) for WoS-indexed journals. Tier } 4 \text { incentive covers articles published in P51 to P75 Scopus-indexed and Q2 } 2 \\
\text { and Q1 WoS-indexed journals. The highest tier (Tier 5) provides incentives to articles published in Scopus-indexed } \\
\text { journals at P76 or higher. The specific incentives in each tier of the revised JPI represent a significant improvement } \\
\text { in the appreciation of research efforts. For example, the maximum incentive amount of the previous incentive } \\
\text { package corresponds to Tier } 2 \text { in the revised JPI such that the highest tier (Tier 5) is about } 400 \% \text { increase in the } \\
\text { previous incentive package of the University. While this entails an increase in the research budget of the University } \\
\text { at the onset, the consequence of its growing research reputation is likewise projected in terms of research grants } \\
\text { availed and recognitions, certifications, and accreditations gained. The next section describes the impact of the } \\
\text { sustained mentoring program and the improved research infrastructure of JRU. }\end{array}$} \\
\hline
\end{tabular}

\section{Findings}

Guided by the transformative and expansive learning frameworks, this participatory action research report focuses on the Scopus metrics of the university, and the paradigm shift among researchers and mentors.

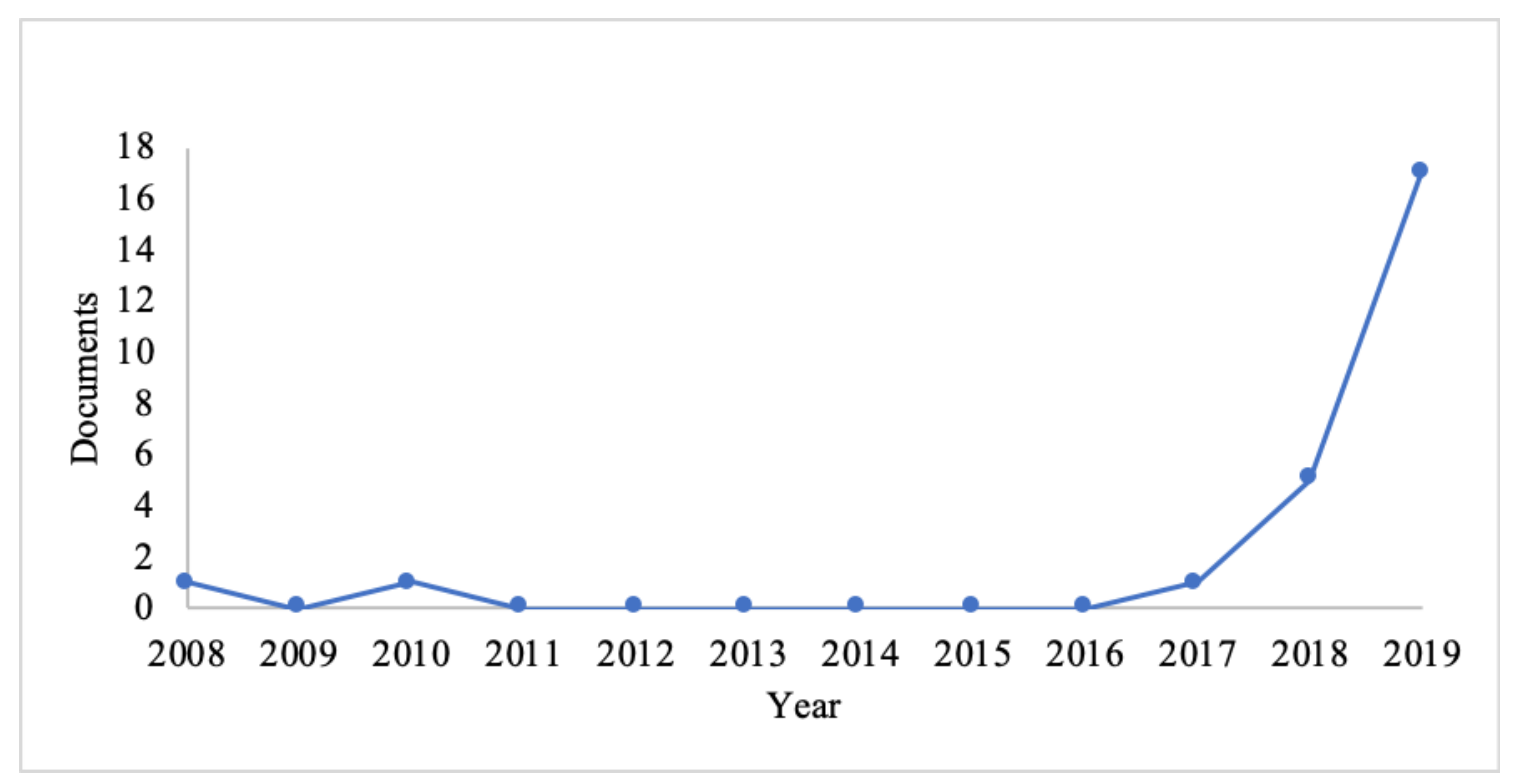

Figure 6. No. of JRU Scopus ${ }^{\circledR}$ documents from 2008 to 2019 (Source: www.scopus.com) 


\subsection{Scopus Metrics}

As of December 31, 2019, the university registered an additional 17 documents in Scopus, an over 200\% increase of the 2018 total Scopus outputs. As can be gleaned from Fig. 6, the Scopus documents of JRU rose to 25, demonstrating a spike in the graph extracted from the Scopus website. In the first quarter of 2020, this figure is expected to rise further due to the seven (7) more articles (in press) accepted for publication in Scopus-indexed journals. While volume and issue numbers are already known for these in press documents, these may reach the Scopus database on a later date. The research office is also monitoring over 15 research articles submitted to Scopus-indexed journals, and about ten others currently being prepared/packaged for submission in Scopus journals.

While the intention of the PAIR mentoring scheme is to have a pair of mentees per mentor, the number of publications per mentee is, however, limitless. As what has happened in our case, mentees were writing at least a pair of articles too to help accelerate the increase of quality research publication in the university. Our six mentees this year (Y1) are all engaged in research, both internally and externally funded. Our team is also currently working on a project that primarily aims to write an action research handbook for the Philippine context.

\subsection{Paradigm Shift}

Change in knowledge and practice among research participants is a crucial element of any participatory research. In this study, we analyzed the reflections of our mentees to draw out indicators of transformation in terms of beliefs, attitudes, understanding, interpretations, and techniques in and about research. We also looked at our reflections about our journey with JRU research. Consolidating our reflections, we present our paradigm shift in research clustered into five themes, representing the research culture we now uphold at JRU.

Connectedness. As exemplified in our PAIR mentoring scheme, researchers switch between mentee and mentor roles in the research process. Crucial to any role in research is the ability of the researcher to connect with the research stakeholders. This entails actively seeking opportunities to teach and to learn. Connecting also entails establishing and sustaining a committed, caring relationship with fellow researchers and other research stakeholders. This manifests as the ability to embrace diversity in paradigms and appreciate synergy and collaboration.

Conviviality. Conviviality is crucial in sustaining a committed and caring relationship in research. It entails projecting warmth and cordiality to all research stakeholders across all stages of the research process Conviviality is also celebrating friendship while maintaining personal boundaries among fellow researchers.

Optimism. Researchers need to foster optimism. Researchers reach a point of exhaustion and desperation or a simple discouragement about the complex and rigorous nature of research. Researchers in this stage need support and encouragement. It is vital to project a reassuring stance with our fellow researchers, especially in the context of a university, when the research journey becomes difficult. Some researchers quickly get discouraged and disappointed, but with a solid mentoring foundation as the PAIR scheme, we always know we have each other's back, whatever happens.

Shared Vision. Shared vision encompasses both manifest and latent visions in research. Manifest visions pertain to the written goals and objectives of the research program. These goals and objectives are the ones we always emphasize to each other through specific metrics and indicators. Beyond these written goals are way more critical visions in any research program. These are the potential impact of the support and camaraderie demonstrated by each element of the research community. It is the confidence in a system where successes are celebrated, and failures are turned into lessons. Shared vision is about committing to engage in research with the intention to inspire others in the team. Shared vision characterizes a research community where every element resonates with the community's purpose and character.

Prudence. Researchers need to exercise prudence at all times. Researchers need to demonstrate a scientific and critical character in all aspects of their personal and professional life. People put high regard to researchers. Hence, researchers are expected to provide well-studied statements and ethics-driven actions. Above all, researchers are expected to direct their actions towards the common good and systemic transformation. In JRU, we see this as a shared vision towards accelerated and continuous improvement of the university research metrics.

\section{Conclusions and Recommendations}

Management of research in higher education is characterized by challenges brought about by our social and cultural constraints, and sometimes by some system-rooted prejudices within the university. Philippine HEIs are no exempt from that. In José Rizal University, while research policies and guidelines have been in place, efforts to accelerate the continuous improvement of research publication metrics have to be instituted. A transformative research 
management paradigm tenders a valuable framework in formulating new models and processes to accelerate research production and publication.

Building from the successful implementation of the PAIR mentoring scheme and the revised guidelines and scope of the university support to research, we tender some recommendations to other HEIs who likewise struggle in their research programs. First, learning and doing research through participatory and transformative paradigms must be advanced in higher education institutions. Research managers must engage with all identified research stakeholders in a system through a series of constructive dialogues and consultations. Research has to be a community (institution-wide) pursuit. Second mentoring should not be just fragments of isolated research capacity-building sessions. It has to be a sustained engagement between the mentor and the mentee in their mutual decision to engage in a committed and caring relationship. The selection of mentors is crucial. Mentors must commit to research and share with the research vision of the university. Third and finally, higher education institutions must institute a research infrastructure that nurtures not just the knowledge and skills in research, but also the attitude and values of its research stakeholders towards research and the overall research program of the organization. While research incentives are deemed powerful tools to inspire the faculty and staff to do research, upholding a community learning perspective in research is equally important. In JRU, while we have seen our Scopus metrics spike this year, we are in a constant watch to sustain the accelerated and continuous improvement of our research metrics.

\section{References}

Anito, J., Morales, M., Torres, M., Gonzales, R. \& Ganeb, M. (2019). Promoting multi-level reflexivity in a model-building qualitative research. [Under Review].

Bradbury, H., Lewis, R. \& Embury, D. (2019). Education Action Research. In C. Mertler, The Wiley Handbook of Action Research in Education (pp. 7-28). New Jersey: John Wiley \& Sons, Inc. https://doi.org/10.1002/9781119399490.ch1

CHED. (2009). National Higher Education Research Agena (NHERA) 2 2009-2018. Quezon City: Commission on Higher Education.

Decena, F. \& Sobrevinas, P. (2017, 10). The Harmonized National R\&D Agenda: Paving the Road to the Fulfillment of the Philippine Development Plan for the Agriculture, Aquatic and Natural Resources Sector through Science and Technology. (F. a. Region, Producer) Retrieved 2019, from FFTC Agricultural Policy Platform: http://ap.fftc.agnet.org/ap_db.php?id=799\&print=1

Engeström, Y. (2016). Studies in expansive learning: Learning what is not yet there. New York, USA: Cambridge University Press. https://doi.org/10.1017/CBO9781316225363

Engeström, Y. (2007). Enriching the Theory of Expansive learning: Lessons from journeys toward coconfiguration. Mind, Culture, and Activity, 23-29. https://doi.org/10.1080/10749030701307689

Engeström, Y. (2004). New forms of learning in co-configuration work. The Journal of Workplace Learning, 11-21. https://doi.org/10.1108/13665620410521477

Engeström, Y. (2001). Expansive learning at work: Toward an activity theoretical reconceptualization. Journal of Education and Work, 133-156. https://doi.org/10.1080/13639080020028747

Engeström, Y. (1987). Learning by expanding: An activity theoretical approach to development research. Helsinki,, Finland: Orienta-Konsultit.

Finefter-Rosenbluh, I. (2017). Incorporating perspective taking in reflexivity: A method to enhance insider qualitative research processes. International Journal of Qualitative Methods, 1-11. https://doi.org/10.1177/1609406917703539

Kindon, S., Pain, R. \& Kesby, M. (2007). Participatory action research approaches and methods: Connecting people, participation, and place. London, UK: Routledge Taylor \& Francis Group. https://doi.org/10.4324/9780203933671

Limjap, A., Miciano, R. \& Mojica, L. (2016). Towards transformative teaching and learning in the college of education: The journey. In A. Bernardo, Counseling, psychology, and education: Essays in honor of Rose Marie Salazar-Clemena (pp. 287-303). Manila: De La Salle University Publishing House.

McNiff, J. \& Whitehead, J. (2002). Action research: Principles and practice. London, UK: Routledge by Taylor \& Francis Group. 
Mertler, C. A. (2017). Action Research: Improving schools and empowering educators. Los Angeles, CA: SAGE Publications, Inc. https://doi.org/10.4135/9781483396484

Mezirow, J. \& Taylor, E. (2009). Transformative learning in practice: Insights from community, workplace, and higher education. San Francisco, CA: Jossey-Bass.

Mills, G. (2011). Action research: A guide for the teacher. Boston: Pearson.

Morales, M., Avilla, R., Anito, J., Elipane, L., Butron, B., Auste, O. \& Casilla, N. (2019). Graduate mentoring program of a State-funded research. [Under Review].

Naples, N. \& Sachs, C. (2000). Standpoint epistemology and the uses of self-reflection in feminist ethnography: Lessons for rural sociology. Rural Sociology, 194-214. https://doi.org/10.1111/j.1549-0831.2000.tb00025.x

Parsons, R. \& Brown, K. (2002). Teacher as reflective practitioner and action researcher. Belmont, CA:: Wadsworth/Thomson Learning.

Pillow, W. (2003). Confession, catharsis, or care? Rethinking the uses of reflexivity as methodological power in qualitative research. International Journal of Qualitative Studies in Education, 175-196. https://doi.org/10.1080/0951839032000060635

Reason, P. \& Bradbury, H. (2008). The SAGE handbook of action research. California: SAGE Pubications Ltd. https://doi.org/10.4135/9781848607934

Republic Act [RA] 7722. (1994). Higher Education Act of 1994. An act creating the Commission on Higher Education, appropriating funds therefor and for other purposes. Manila, Philippines.

Riel, M. (2007). Understanding Action Research. Retrieved from Center for Collaborative Action Research: http://cadres.pepperdine.edu/ccar/define.html

Salazar-Clemeña, R. M. (2006). Higher education research in the Philippines: Policies, practices, and problems. In V. Meek \& C. Suwanwela, Higher Education, Research, and Knowledge in the Asia-Pacific Region (pp. 185-200). New York: Palgrave Macmillan. https://doi.org/10.1057/9780230603165_10

Scimago. (2018). Scimago Journal and Country Ranking. (S. I. Rankings, Producer) Retrieved 2019, from Scimago: https://www.scimagojr.com

Shaw, I. \& Gould, N. (2001). Qualitative research in social work. London, England: Sage. https://doi.org/10.4135/9781849209694

Stringer, E. (2007). Action Research. Thousand Oaks, CA: SAGE Publications, Inc.

Stronach, I., Garratt, D., Pearce, C. \& Piper, H. (2007). Reflexivity, the picturing of selves, the forging of method. The Qualitative Inquiry. https://doi.org/10.1177/1077800406295476 